\title{
Inventário florístico florestal de Santa Catarina (IFFSC): aspectos metodológicos e operacionais
}

\author{
Alexander Christian Vibrans¹, Lúcia Sevgnani', Débora Vanessa Lingner ${ }^{1}$, André Luis de Gasper ${ }^{1}$, Shams Sabbagh ${ }^{1}$ \\ 1Universidade Regional de Blumenau (FURB), Rua São Paulo, 3250, CEP 89030-000, Blumenau, SC, Brasil, acv@furb.br; sevegn@furb.br; \\ deboravanessa.ef@gmail.com; algasper@gmail.com; sabbagh.chajara@gmail.com
}

\begin{abstract}
Resumo - O objetivo do presente trabalho é contribuir à discussão sobre inventários florestais de abrangência regional e nacional, com enfoque em suas metodologias e em sua execução. O Inventário Florístico Florestal de Santa Catarina (IFFSC), iniciativa do governo estadual, foi concebido em 2003 para atender exigências da legislação ambiental. Após o inventário-piloto em 2005, a metodologia foi adequada em 2007 de acordo com a proposta do Inventário Florestal Nacional (IFN-BR), à época, sob discussão. O IFFSC, em execução desde 2007, abrange todas as regiões fitoecológicas, incluindo levantamento florístico (coleta de amostras das espécies férteis encontradas no interior e entorno dos fragmentos visitados) e levantamento de epífitas vasculares por equipes especializadas. A distribuição das unidades amostrais é sistemática, a partir de uma grade de pontos com distância de $10 \mathrm{~km} \times 10 \mathrm{~km}$, cobrindo todo o estado e de $5 \mathrm{~km} \times 5 \mathrm{~km}$ na reduzida Floresta Estacional Decidual. O método de amostragem é o de área fixa em conglomerados compostos por quatro subunidades com área de $1.000 \mathrm{~m}^{2}(20 \mathrm{~m} \times 50 \mathrm{~m})$, perpendiculares a partir de um ponto central. As abordagens metodológicas e operacionais são discutidas a partir do trabalho efetuado entre 2007 e 2010 . O aumento da intensidade amostral e a diminuição dos limites de inclusão de diâmetro e altura nos estratos arbóreo e da regeneração, em relação à proposta do IFN-BR, bem como a realização do levantamento florístico mostraram-se importantes para o registro da diversidade vegetal das florestas catarinenses.
\end{abstract}

Termos para indexação: Inventário Florestal; levantamento florístico; Mata Atlântica.

\section{The Floristic and Forest Inventory of Santa Catarina State (IFFSC): methodological and operational aspects}

\begin{abstract}
The purpose of this study is to contribute to the discussion on regional and national forest inventories, aiming mainly on aspects of methodos and operational. The Floristic and Forest Inventory of Santa Catarina State (IFFSC) is an initiative of the state government and it was conceived in order to attend requirements of environmental laws. A pilot inventory took place in 2005; then the methodology was fitted to the proposal of the National Forest Inventory (IFN-BR) in discussion at the time. IFFSC is carried out since 2007 in all natural forest formations all over the state's territory, including floristic sampling (collection of fertile trees, shrubs and herbs within the sample unit and in its surroundings) and survey of vascular epiphytes by specialized crews. The inventory applies a systematic sampling, with sample units containing clusters of four crosswise $1,000 \mathrm{~m}^{2}$ plots $(20 \mathrm{~m}$ x $50 \mathrm{~m})$, distributed systematically at the intersections of a $10 \mathrm{~km}$ x $10 \mathrm{~km}$ grid all over the state's territory (a $5 \mathrm{~km}$ x $5 \mathrm{~km}$ grid is applied on highly fragmentized Seasonal Deciduous Forests). Methodological details and some important operational issues are discussed beyond the four years experience of IFFSC. Major sampling intensity and lower diameter and height thresholds (in the arboreal and regeneration strata) than in the nationwide inventory proposal (IFN-BR), as well as the execution of a floristic survey within and around the sample plots, showed to be important to record plant diversity of Santa Catarina's forests.
\end{abstract}

Index terms: Forest inventory; floristic survey; atlantic rain forest.

\section{Introdução}

O inventário florestal é o processo de obtenção de dados qualitativos e quantitativos dos recursos florestais. Ele é base para o manejo, para a conservação das florestas, para o planejamento regional e fundamenta a tomada de decisões estratégicas nos diversos níveis administrativos. Além das demandas internas, acordos internacionais como a Convenção sobre Diversidade Biológica (CBD, 1993), o Protocolo de Kyoto (United Nations, 1998) do United Nations Framework Convention on Climate Change (UNFCCC) e levantamentos globais como o 
Forest Resource Assessment (FAO, 2009), da Food and Agriculture Organization of the United Nations (FAO), requerem que as nações signatárias informem suas áreas de florestas e emitam relatórios sobre o estado destas (Tomppo et al., 2010). No Brasil, discute-se a realização de um novo inventário florestal nacional (IFN-BR) desde o início deste século, uma vez que o último levantamento ocorreu na década de 1980 (IBDF, 1984, entre outros volumes), ainda realizado com foco exclusivo nos recursos madeireiros. Durante os anos de 2006 e 2007, a Comissão Técnica Nacional (CTN-IFN/BR), instituída em 2005 pelo Ministério do Meio Ambiente, constituiu o fórum de uma discussão nacional sobre o assunto, o que culminou na redação de uma proposta metodológica para o Inventário Florestal Nacional do Brasil (CTN-IFN/BR, 2007; Freitas et al., 2010).

Como a maioria dos estados brasileiros, Santa Catarina também não possuía informações atualizadas, detalhadas e confiáveis sobre a sua cobertura florestal natural. No entanto, o conhecimento da extensão territorial da cobertura florestal, sua composição florística, estrutura e estado de conservação, é considerado imprescindível para a formulação de uma política florestal. Esta deve abranger tanto os aspectos técnicos e socioeconômicos do uso dos recursos florestais, como as necessidades de conservação e preservação de ecossistemas em espaços territoriais específicos (Unidades de Conservação) e de espécies da flora e fauna ameaçadas de extinção.

A atualização das informações quali-quantitativas, através de um novo inventário florestal, começou a ser discutida em Santa Catarina em 2003, motivada pelas Resoluções $n^{0}$ 278/2001 e no 309/2002 do Conama (Brasil, 2001, 2002), que vinculam autorizações para corte e exploração de espécies ameaçadas de extinção, constantes da lista oficial do Ibama, em populações naturais no bioma Mata Atlântica, à elaboração de "critérios técnicos, baseados em inventário florestal que garantam a sustentabilidade da exploração e a conservação genética das populações" (Art. $1^{\circ}$ da Resolução 278/2001 do CONAMA).

Desta forma, em Santa Catarina, especial atenção foi atribuída à investigação das espécies ameaçadas, resultando em duas componentes adicionais que ultrapassam as atividades tradicionais de inventário florestal: a) a atualização dos levantamentos florísticos realizados nas décadas de 1950 e 1960 em conjunto com a integração dos acervos dos herbários existentes no estado e, b) o estudo da estrutura genética de populações de espécies da flora ameaçadas de extinção.

Levantamentos sistemáticos da flora catarinense foram realizados nas décadas de 1950 a 1970 e geraram um grande conjunto de informações florísticas, culminando com a publicação da Flora Ilustrada Catarinense (Reitz, 1965 -), que colocaram o Estado de Santa Catarina numa posição privilegiada entre os demais estados brasileiros em relação ao conhecimento de sua flora. O último levantamento sistemático e quantitativo das florestas catarinenses data da década de 1980 (IBDF, 1984). Atendendo às demandas supracitadas, o Inventário Florístico Florestal de Santa Catarina (IFFSC) foi iniciado em 2005, com recursos estaduais e federais, através de um inventário-piloto da Floresta Ombrófila Mista (Vibrans et al., 2008). Após uma fase de ajustes metodológicos e conceituais, o IFFSC teve continuação através da execução do levantamento definitivo em todo o estado, a partir de novembro de 2007 . Foram realizadas as fases 2 (2007-2008), 3 (2008-2009) e 4 (2009-2010), financiadas pelo governo estadual, através da Fundação de Apoio à Pesquisa Científica e Tecnológica do Esatado de Santa Catarina (Fapesc). Desde 2007, o IFFSC está utilizando metodologia compatível com a proposta para o Inventário Florestal Nacional (CTN-IFN/BR, 2007).

O Inventário Florístico Florestal de Santa Catarina (IFFSC) sensu lato tem como grandes metas: 1) o inventário terrestre da estrutura e composição florística das florestas do estado (componentes arbóreo, arbustivo, herbáceo e das epífitas vasculares), ou seja, o IFFSC sensu stricto; 2) a informatização dos herbários do estado; 3) a caracterização genética de populações de espécies ameaçadas; 4) a avaliação socioeconômica dos recursos florestais e, 5) a criação de um sistema de informações florestais georeferenciadas. Neste trabalho será abordada apenas a primeira meta, que é de responsabilidade da Universidade Regional de Blumenau (FURB).

Neste sentido, o presente trabalho teve como objetivo descrever e discutir a metodologia do IFFSC sensu stricto e apresentar os aspectos de sua operacionalização, baseado no trabalho efetuado no período de 2007 a 2010, bem como alguns dos resultados preliminares da primeira meta. 


\section{Metodologia do IFFSC}

\section{Processo e método de amostragem}

Em conformidade com a proposta para o Inventário Florestal Nacional do Brasil (IFN-BR) (CT-IFN/BR, 2007) e com base nos estudos de Péllico Netto (1979), Brena (1995) e Queiroz (1997), o inventário catarinense foi estruturado utilizando o processo de amostragem de múltiplas ocasiões com possibilidade de repetição total da amostragem, com distribuição sistemática das unidades amostrais (UAs), a partir de uma rede de pontos sistematizados (grade), cobrindo todo o estado. A seleção das UAs foi realizada a partir de uma estratificação preliminar em floresta e não floresta, baseada em interpretação de imagens orbitais. Adotouse para a definição de "floresta" a definição da FAO (2009): terras com área mínima de 0,5 ha, árvores com altura $>5 \mathrm{~m}$ e cobertura das copas $\geq 10 \%$. O método de amostragem foi o de Área Fixa em Conglomerados compostos por quatro subunidades perpendiculares a partir de um ponto central. O processo de amostragem com repetição total exige que a estrutura amostral seja permanente para que as UAs possam ser remedidas. As UAs foram demarcadas com hastes de ferro galvanizado, enterradas para futura localização com detector de metal.

\section{Locação dos pontos amostrais}

Para a materialização dos pontos amostrais e a implantação das respectivas UAs, foi definida pela Embrapa Florestas uma grade de pontos com distância de $10 \mathrm{~km}$ x $10 \mathrm{~km}$, em coordenadas UTM, com datum WGS 84. Para os remanescentes da Floresta Estacional Decidual (FED), extremamente reduzida e fragmentada, foi adotada uma grade de $5 \mathrm{~km} \times 5 \mathrm{~km}$ para assegurar um número suficiente de UAs que possibilitasse a documentação da diversidade dos componentes arbóreo e arbustivo nos remanescentes existentes, incluídas as espécies raras e as ameaçadas de extinção e a análise quantitativa e estatística dos dados.

\section{Fontes de dados espaciais}

Foram utilizadas como base cartográfica as cartas topográficas do Mapeamento Sistemático Brasileiro na escala de 1:50.000 e 1:100.000, em formato digital. O IFFSC utilizou como divisão fitogeográfica da vegetação aquela proposta por Klein (1978). De acordo com este mapa fitogeográfico, a Floresta Ombrófila Mista (FOM) cobria originalmente $43 \%$ da superfície do estado, a Estepe 14\%, a Floresta Ombrófila Densa (FOD) 30\% e a Floresta Estacional Decidual (FED) 8\%. Para apoiar o inventário de Santa Catarina, foi realizado o mapeamento dos remanescentes florestais e do uso do solo através de interpretação visual de imagens orbitais multiespectrais dos satélites Landsat-5 TM e Landsat-7 ETM+ dos anos de 2003 e 2004 (SAR, 2005) e de classificação não supervisionada de imagens multiespectrais dos satélites SPOT-4 e SPOT-5 do ano de 2005 (Fundação do Meio Ambiente de Santa Catarina, 2008). De acordo com os resultados destes levantamentos, o Estado de Santa Catarina possui uma cobertura florestal natural remanescente de aproximadamente $35.500 \mathrm{~km}^{2}(37,2 \%$ do território), considerando áreas maiores que 10 ha.

\section{Intensidade da amostragem}

Os locais para os quais os mapeamentos temáticos indicaram a existência de florestas constituíram os pontos para a instalação de UA e coleta de dados de campo. Locando a grade de $20 \mathrm{~km} \times 20 \mathrm{~km}$ proposta para o IFN/BR sobre o mapa dos remanescentes florestais, foram obtidas 86 UAs para todo o estado, sendo três para a FED, 46 para a FOM e 37 para a FOD. Esta intensidade amostral foi considerada insuficiente para atender aos objetivos propostos para o IFFSC. Um inventário-piloto, realizado em 2005 na Floresta Ombrófila Mista, resultou numa suficiência amostral de 97 UAs para alcançar um erro amostral de $10 \%$ para a variável área basal com um nível de probabilidade de 5\%. A utilização de grades de $10 \mathrm{~km} \times 10 \mathrm{~km}$ (para a FOM e para a FOD) e de $5 \mathrm{~km}$ x $5 \mathrm{~km}$ (para a FED), ambas frações da grade do IFN e, portanto, em partes coincidentes, resultou em 550 UAs para todo o estado (Figura 1), o que possibilitou alcançar o erro amostral acima mencionado em cada uma das três regiões fitoecológicas. 


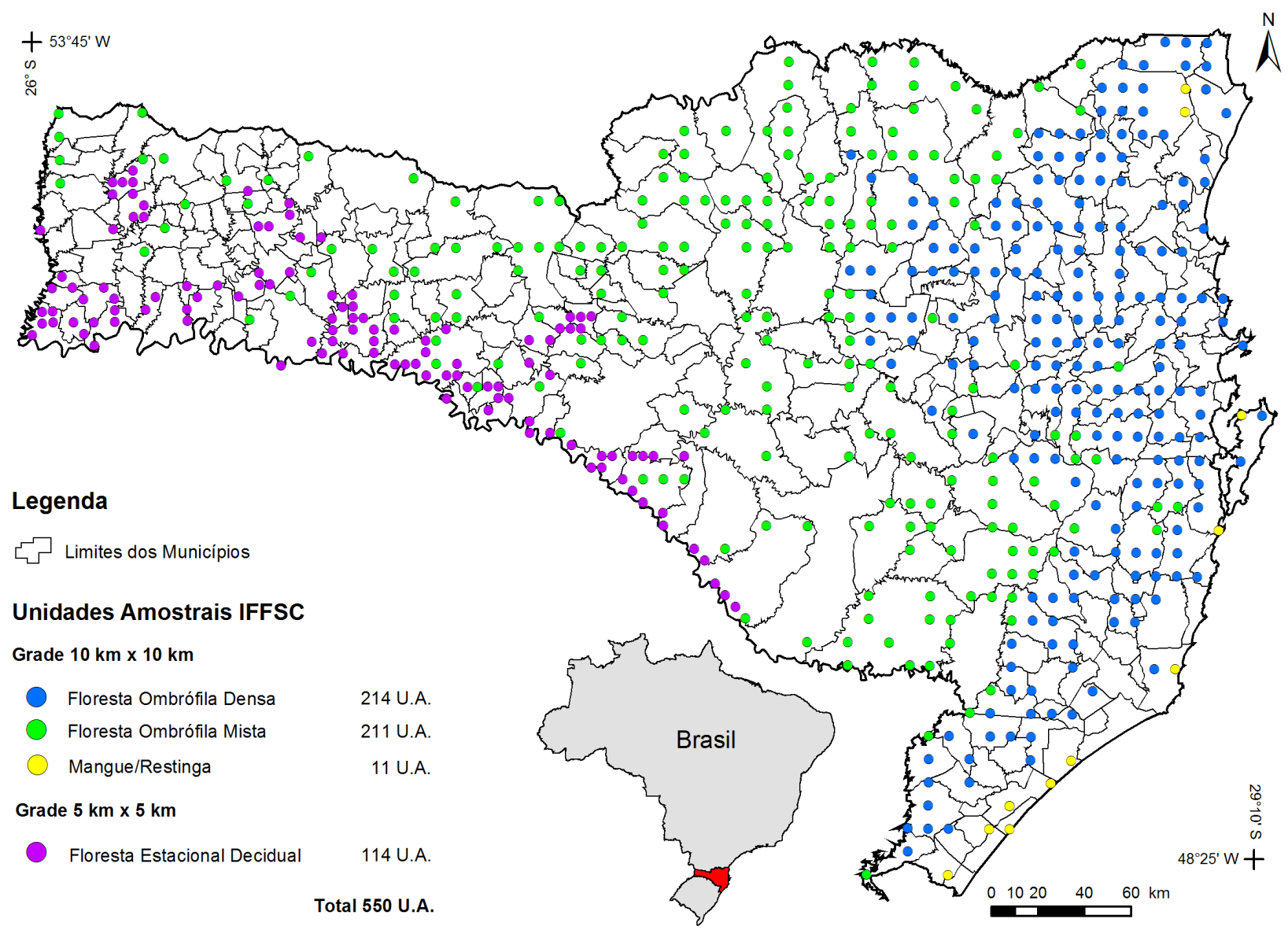

Figura 1. Localização das 550 unidades amostrais do IFFSC no Estado de Santa Catarina, por região fitoecológica.

\section{Unidade amostral (UA)}

Cada UA foi composta por um conglomerado com área total de $4.000 \mathrm{~m}^{2}$, constituído por quatro subunidades, com área de $1.000 \mathrm{~m}^{2}$ cada, medindo $20 \mathrm{~m}$ de largura e $50 \mathrm{~m}$ de comprimento, orientadas na direção dos quatro pontos cardeais (norte, sul, leste e oeste), mantendo, cada uma, $30 \mathrm{~m}$ de distância do centro do conglomerado, com área de inclusão de 2,56 ha (Figura 2). Cada subunidade de $20 \mathrm{~m}$ x $50 \mathrm{~m}$ foi constituída por 10 unidades básicas de $10 \mathrm{~m}$ x $10 \mathrm{~m}\left(100 \mathrm{~m}^{2}\right)$, onde se efetuou o levantamento de todos os indivíduos com diâmetro à altura do peito maior ou igual a $10 \mathrm{~cm}(\mathrm{DAP} \geq 10 \mathrm{~cm})$. Destes, foram registradas as suas coordenadas $\mathrm{x}$ e y dentro da subunidade, de modo a possibilitar o processamento dos dados com base na unidade básica de $100 \mathrm{~m}^{2}$, bem como facilitar o controle de qualidade do trabalho de campo e futuras remedições. Cada subunidade contém uma subparcela de $5 \mathrm{~m} \times 5 \mathrm{~m}$, destinada ao levantamento da regeneração natural, considerando as plantas com altura $\geq 1,50 \mathrm{~m}$ e DAP $<10 \mathrm{~cm}$, embora sejam nelas incluídas, além de indivíduos jovens de espécies do dossel, também espécimes exclusivas do sub-bosque. Após levantamento da FOM e da FED, considerando ainda o trabalho de Calegari (1999), que resultou numa área ótima de amostragem da regeneração de $64 \mathrm{~m}^{2}$ para a FOM no Rio Grande do Sul, decidiu-se intensificar a amostragem deste estrato na FOD e levantar quatro subparcelas de $5 \mathrm{~m} \times 5 \mathrm{~m}$ por subunidade, localizadas nas extremidades delas (Figura 2), avaliando as plantas com altura $\geq 0,50 \mathrm{~m}$.

Os principais equipamentos de medição usados pelas equipes foram: trena a laser, fita métrica, hipsômetro, binóculo, máquina fotográfica digital, trenas, balisas, estilingue, tesoura de poda com cabo estendido e radiocomunicador.

Para o levantamento da necromassa lenhosa e quantificação do carbono estocado neste compartimento, foram instaladas quatro unidades lineares (transectos) de 
$5 \mathrm{~m}$ de comprimento, a partir do centro do conglomerado, sendo uma em cada quadrante, totalizando $20 \mathrm{~m}$ lineares por conglomerado, utilizando o método de amostragem de necromassa por transecto (Shiver \& Borders, 1996) e medindo a circunferência $(\geq 3 \mathrm{~cm}$ ) de todo material lenhoso morto encontrado na linha do transecto. Duas amostras de solo foram coletadas no centro do conglomerado, nas profundidades de $0-20 \mathrm{~cm}$ e $30-50 \mathrm{~cm}$, igualmente destinadas à estimativa do carbono estocado no solo.

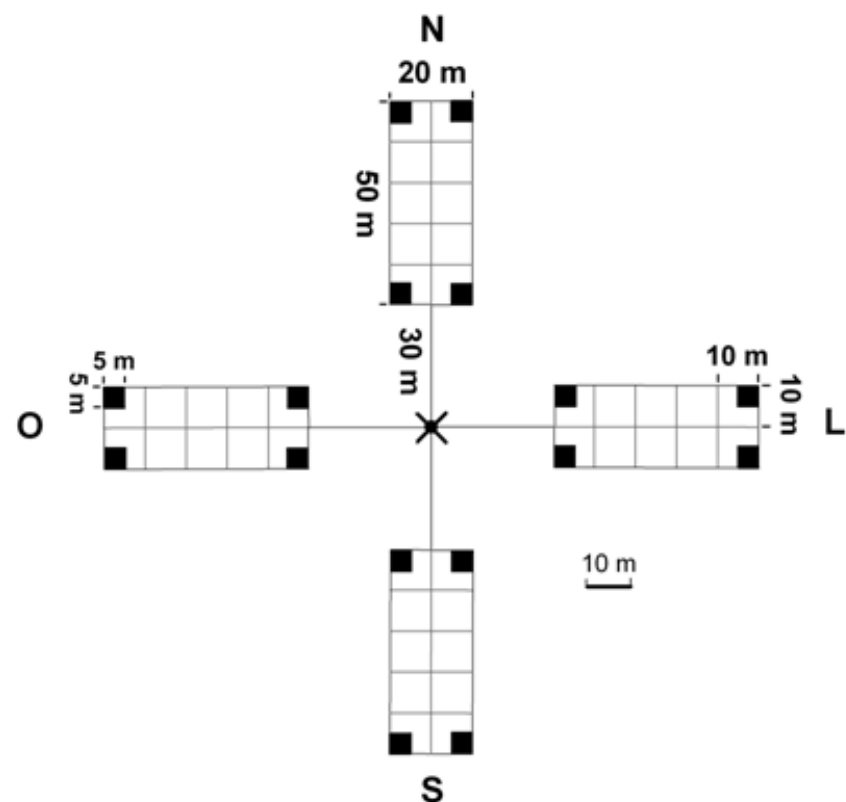

Figura 2. Estrutura do conglomerado básico do IFFSC (para a Floresta Ombrófila Densa).

\section{Dados gerais da unidade amostral}

Para cada UA foram registrados na ficha de campo (em papel) a data da visita, local e coordenadas de origem (local de hospedagem) e de acesso à UA, tempo para chegar ao acesso e à UA, localidade, município, proprietário, aspectos físicos como exposição, relevo, declividade e as características gerais da vegetação no fragmento e no seu entorno, de acordo com a proposta do IFN-BR. No caso das UA, cujos pontos foram visitados, porém sem poder instalá-las (que são chamadas "UAs descartadas"), ainda foi anotado o motivo do "descarte". As equipes de campo elaboraram uma detalhada descrição fisionômica da vegetação encontrada dentro da UA e no seu entorno. Constam desta descrição os principais aspectos da vegetação (altura da comunidade, fechamento do dossel, espécies marcantes da fisionomia e os principais fatores antrópicos de perturbação), bem como a classificação fitoecológica, seus estágios de sucessão e de conservação, como percebidos em campo, portanto, não baseados nos dados processados.

\section{Variáveis dendrométricas levantadas}

As principais variáveis dendrométricas coletadas e registradas em ficha de campo para cada indivíduo do componente arbóreo e arbustivo da unidade básica $(10 \mathrm{~m}$ x $10 \mathrm{~m})$ foram: número sequencial; nome científico; circunferência à altura do peito (CAP) em $\mathrm{cm}$; altura comercial (estimada visualmente); altura total (estimada visualmente); qualidade do fuste, sanidade da árvore, posição sociológica; presença de lianas e epífitas; registro se a planta foi coletada e o número do coletor (na listagem sequencial do biólogo da equipe).

A mensuração do CAP foi realizada com fita métrica (com marcação da altura correta de 1,30 m no uniforme dos integrantes da equipe). A marcação da altura exata da medição nas árvores com tinta não foi realizada por representar uma demanda de tempo, à época considerada excessiva, mas deverá ocorrer em futuros levantamentos. Em cada subunidade de $20 \mathrm{~m} \times 50 \mathrm{~m}$ foram medidas, com hipsômetro, as alturas comercial e total de duas árvores, abrangendo todas as classes diamétricas. Estas medições foram realizadas para ajustar modelos hipsométricos por espécie e grupo de espécies e para aferir as estimativas visuais das alturas das demais árvores realizadas pelo engenheiro da equipe. Nas subparcelas de $5 \mathrm{~m}$ x $5 \mathrm{~m}$, os indivíduos incluídos foram identificados (coletados) e registradas as suas alturas estimadas em campo.

\section{Cubagem de árvores}

Para estimativas de volume e biomassa é imprescindível o uso de equações de volume específicas para as espécies das florestas do Sul do Brasil. As informações necessárias para o ajuste dos modelos volumétricos foram coletadas através da cubagem de duas árvores em pé por subunidade, totalizando oito árvores por UA. Este trabalho foi realizado pelo escalador da equipe, por vezes em árvores que também foram escaladas para coleta de material botânico, buscando, no entanto, contemplar diferentes grupos de espécies e classes de diâmetro. De baixo para cima, as medidas dos diâmetros em diferentes alturas foram tomadas com fita métrica a $0,3 \mathrm{~m}$ (toco); $1 \mathrm{~m} ; 1,3 \mathrm{~m} ; 2 \mathrm{~m} ; 3 \mathrm{~m}$ e assim sucessivamente de $1 \mathrm{em} 1$ metro ao longo do fuste até o início da copa, levantando, desta forma, os dados do fuste de 728 árvores na FOM, 303 na FED e (até abril de 2010) 767 na FOD. 


\section{Coleta de material botânico}

De todas as plantas não indubitavelmente identificadas em campo foram coletadas amostras, preferencialmente férteis, mas também estéreis, para herborização e posterior identificação, conforme procedimentos usuais e para incorporação ao Herbário Roberto Miguel Klein (FURB). Para coleta do material botânico foram usados, além de equipamentos de escalada, binóculo (10 x 25), tesoura de poda com cabo estendido de $5 \mathrm{~m}$ e estilingue. Todas as plantas coletadas durante o dia foram prensadas à noite em jornal e treliças de madeira, encharcadas em álcool 70\% e fechadas em saco plástico. $\mathrm{O}$ envio das plantas para o laboratório precisava ser feito semanalmente, principalmente nos meses de verão, através de despacho por empresas de ônibus ou por veículo de apoio. Das coletas férteis, foram separadas até cinco duplicatas para permuta; as plantas estéreis foram armazenadas no herbário em separado; destas, um exemplar foi tombado como testemunha quando, até o final dos levantamentos, não foi coletada uma amostra fértil da mesma espécie.

\section{Plantas herbáceas terrícolas e epífitas}

Nas fases 2 e 3, as plantas herbáceas terrícolas férteis, bem como lianas férteis, quando ao alcance a partir do solo, foram coletadas dentro e ao redor da UA, assim como ao longo da trilha de acesso. A presença de taquaras e bambus foi registrada e coletada, quando fértil, porém não quantificada. Estes procedimentos foram mantidos na FOD (fase 4).

O levantamento das epífitas vasculares férteis no inventário-piloto (fase 1) foi realizado através da coleta das epífitas sobre dois forófitos sorteados em cada UA. Isto mostrou-se inadequado por não gerar resultados satisfatórios e representativos, como baixo número de material fértil coletado e, consequentemente, o pequeno número de espécies identificadas.

Nas fases 2 e 3 (FOM, planalto catarinense, e FED), o levantamento florístico das epífitas vasculares foi realizado em dois forófitos de diferentes classes de diâmetro por subunidade amostral, escolhidos pela equipe entre os que apresentavam a maior diversidade de plantas daquele grupo. Além disso, foram coletadas epífitas férteis ao alcance da mão e da tesoura de poda com cabo estendido. Este procedimento também resultou em pequena amostragem das espécies devido à falta de um deslocamento sobre a copa e de uma observação mais acurada.
Devido à grande riqueza e densidade de epífitas vasculares naFOD e pela especificidade da metodologia de sua coleta e identificação, seu levantamento foi realizado por duas equipes especializadas, que trabalharam independentemente daquelas do levantamento do componente arbóreo. Foram selecionadas $30 \mathrm{UAs}$, entre as 208 UAs regulares (em florestas bem conservadas, com maior diversidade aparente de epífitas, observados gradientes de altitudes, latitude e longitude). Estas foram visitadas no mínimo três vezes com intervalo de três meses entre cada visita, para encontrar indivíduos férteis do maior número possível de espécies.

$\mathrm{Na}$ área da UA, definida por um círculo com raio de $80 \mathrm{~m}$ em torno do ponto central, o escalador e o assistente realizavam registro e coleta de plantas epifíticas férteis no tronco e no alto das copas de oito árvores de grande porte (forófitos), usando técnicas de arvorismo. Em solo, um biólogo com auxiliar percorria a área da UA para coletar espécies epifíticas sobre árvores e galhos caídos, arvoretas, lianas e fetos arborescentes e realizar registro fotográfico. Espécimes estéreis, quando identificados em campo, foram registrados, para auxiliar na análise da distribuição espacial das espécies em Santa Catarina, porém não coletados.

\section{Aspectos operacionais}

\section{Composição das equipes de campo}

As equipes de campo para os levantamentos do componente arbóreo foram compostas por um engenheiro florestal (líder de equipe), um biólogo, três auxiliares e um escalador, treinados num período de duas semanas em campo, sendo o último com curso de 40 horas-aula de escalada, ministrado por profissionais experientes. As equipes para levantamento de epífitas foram compostas por um biólogo especializado neste grupo (líder), um rapelista (biólogo) com experiência em arvorismo e treinado para observar e coletar epífitas e dois auxiliares de coleta. As equipes foram treinadas em direção defensiva, primeiros socorros e equipadas com rádio-comunicadores e localizador de emergência.

\section{Composição das equipes de apoio e processamento de dados}

O IFFSC foi planejado e gerenciado por um grupo de professores da Universidade Regional de Blumenau, sendo três engenheiros florestais e uma bióloga. A equipe de apoio logístico e processamento de dados 
foi constituída por dois auxiliares administrativos, dois engenheiros florestais e quatro bolsistas de graduação em engenharia florestal. A equipe do herbário foi formada por um biólogo responsável e cinco bolsistas, para recebimento, prensagem, secagem, montagem, costura e cadastro das exsicatas, além do correto armazenamento na coleção geral.

\section{Herbário}

A existência de um herbário com rotinas de trabalho bem estabelecidas e a integração das atividades do herbário com as da equipe de processamento de dados mostraram-se fundamental para o bom andamento do trabalho. Aproximadamente $30 \%$ das plantas registradas pelas equipes de campo passaram pelo herbário, como espécimes estéreis ou férteis. Isto significou um volume de cerca de 87.000 plantas processadas até junho de 2010 (Tabela 1), faltando ainda o processamento das coletas de $20 \%$ das UAs da FOD, o que exigiu espaço físico adequado, equipamentos como freezeres, prensas e estufas com capacidade suficiente e pessoal treinado.

Tabela 1. Quantidade de plantas férteis (F) e estéreis (E) processadas no herbário FURB entre novembro de 2007 e junho de 2010, por forma de vida e região fitoecológica. Os dados da FOD incluem apenas 169 das 208 UAs previstas.

\begin{tabular}{cccccrrrrrr}
\hline $\begin{array}{c}\text { Região } \\
\text { fitoecológica }\end{array}$ & \multicolumn{2}{c}{$\begin{array}{c}\text { Total de plantas } \\
\text { processadas }\end{array}$} & \multicolumn{2}{c}{ Arbóreas e arbustivas } & \multicolumn{2}{c}{$\begin{array}{c}\text { Herbáceas } \\
\text { terrícolas }\end{array}$} & Epífitas & Pteridófitas \\
\hline & \multicolumn{1}{c}{$\mathrm{F}^{(1)}$} & $\mathrm{E}$ & $\mathrm{F}^{(1)}$ & $\mathrm{E}$ & $\mathrm{F}^{(1)}$ & $\mathrm{E}$ & $\mathrm{F}^{(1)}$ & $\mathrm{E}$ & $\mathrm{F}^{(1)}$ \\
FOM & 16.360 & 5.756 & 7.450 & 5.269 & 4.130 & 338 & 4.220 & 153 & 4.160 \\
FED & 5.600 & 1.646 & 2.800 & 1.530 & 1.470 & 119 & 680 & 0 & 940 \\
FOD & 65.870 & 11.614 & 19.850 & 11.528 & 10.200 & 5 & 15.800 & 77 & 13.400 \\
Total & 87.830 & 19.016 & 30.100 & 18.327 & 15.800 & 462 & 20.700 & 230 & 18.500 \\
\hline
\end{tabular}

(1) incluídas três duplicatas, em média.

\section{Localização da Unidade Amostral}

Foram elaborados mapas de orientação na escala de 1:100.000 e de cada ponto amostral um mapa detalhado na escala de 1:20.000, além de recortes de imagens satelitais ortoretificadas, com o provável trajeto de acesso à UA, também gravado na memória do aparelho GPS. As equipes usaram aparelho GPS Garmin 76 CSx Map, que permitiu localizar o ponto amostral também sob dossel da floresta. Com a crescente disponibilidade de serviços Google Earth e o aumento da resolução espacial de suas imagens, estas também foram consultadas e usadas pelas equipes em laptop no local da hospedagem. Diante das dificuldades na localização e no acesso às UAs encontradas nas fases 2 e 3 , foi implementada na fase 4 uma etapa de reconhecimento prévio das UAs: os engenheiros e biólogos de cada equipe verificavam previamente em sua área de atuação o acesso a cada UA, contatando os proprietários e os agrônomos extensionistas locais.

\section{Rendimento das equipes}

$\mathrm{O}$ rendimento das equipes de campo foi influenciado por uma série de fatores, entre condições meteorológicas e de acesso, topografia do local e densidade da vegetação. O tempo necessário para levantamento de uma UA foi de 1,5 dias para a FOM e a FED, e de três dias para a
FOD. As equipes de epífitas levaram em média três dias para concluir o levantamento de uma UA. Na Tabela 2 é apresentado o tempo gasto por região fitoecológica e tipo de atividade, como deslocamento do hotel ao ponto de acesso e caminhamento do veículo até a UA e medição. Devido à maior densidade e diversidade da vegetação, o tempo de medição na FOD é duas vezes maior que na FED e FOM, embora também a intensificação da amostragem da regeneração tenha contribuído para este aumento. Nos remanescentes da FOM não foi possível instalar $22,3 \%$ das unidades previstas, na FED foram descartadas $12,3 \%$ das UA, enquanto na FOD este percentual foi menor que 5\%. Impossibilitaram a realização da medição condições adversas de acesso, ausência ou tamanho reduzido do fragmento florestal (uma UA era descartada se menos que 60\% da superfície dela fosse coberta por florestas), alteração recente do uso do solo, ou a falta de autorização dos proprietários. Além destes descartes decididos em campo, outras UAs já foram eliminadas no escritório com base na análise de imagens satelitais mais recentes e com maior resolução espacial (6,2\% na FOM, $17,5 \%$ na FED e $2,8 \%$ na FOD).

Em média, foram registrados na FOM 331 fustes, equivalentes a 295 indivíduos (Tabela 3); na FED este número foi menor (251 e 219, respectivamente). Na FOD 
o número de fustes registrados foi $69 \%$ maior que na FOM e $125 \%$ maior que na FED. O número de plantas medidas no estrato DAP $\geq 10 \mathrm{~cm}$ foi igual na FOM e na FOD, mas foi $32 \%$ menor na FED. As plantas com $\mathrm{DAP}<10 \mathrm{~cm}$ foram quase duas vezes mais abundantes na FOM do que nas demais formações (considerando a mesma área amostral). A maior área amostral na FOD levou ao registro de 278 plantas por UA neste estrato.
As equipes ainda coletaram em média 40 plantas estéreis e 41 plantas férteis por UA, com diferenças relevantes entre as regiões fitoecológicas. Deve-se considerar relevante o tempo dispendido para processamento das amostras de plantas coletadas (prensar, registrar em caderno de coleta e embalar), realizado à noite logo ao chegar ao hotel, devido à fragilidade e efemeridade das flores e frutos, levando em média duas horas.

Tabela 2. Tempo médio de acesso e medição, por Unidade Amostral (UA) e por região fitoecológica do IFFSC. Os dados da FOD incluem apenas 169 das 208 UAs previstas.

\begin{tabular}{crcc} 
Região fitoecológica & $\begin{array}{c}\text { Tempo de acesso } \\
\text { (do hotel ao acesso) }\end{array}$ & $\begin{array}{c}\text { Tempo de caminhamento } \\
\text { (do acesso à UA) }\end{array}$ & Tempo de medição \\
\hline FOM & $1 \mathrm{~h} 21 \mathrm{~min}$ & $47 \mathrm{~min}$ & $7 \mathrm{~h} 50 \mathrm{~min}$ \\
FED & $1 \mathrm{~h} 07 \mathrm{~min}$ & $42 \mathrm{~min}$ & $7 \mathrm{~h} 24 \mathrm{~min}$ \\
FOD & $48 \mathrm{~min}$ & $44 \mathrm{~min}$ & $16 \mathrm{~h} 21 \mathrm{~min}$ \\
\hline Média & $1 \mathrm{~h} 05 \mathrm{~min}$ & $44 \mathrm{~min}$ & $10 \mathrm{~h} 31 \mathrm{~min}$ \\
\hline
\end{tabular}

Tabela 3. Número médio de plantas registradas e coletadas por Unidade Amostral (UA), estrato e Região Fitoecológica do IFFSC. Os dados da FOD incluem apenas 169 das 208 UAs previstas.

\begin{tabular}{cccccc}
\hline Região fitoecológica & $\begin{array}{c}\text { Registros } \\
\text { (fustes) }^{(\mathbf{1})}\end{array}$ & $\begin{array}{c}\text { Plantas } \\
\mathbf{D A P} \geq \mathbf{1 0} \mathbf{~ c m}\end{array}$ & $\begin{array}{c}\text { Plantas } \\
\mathbf{D A P}<\mathbf{1 0} \mathbf{~ c m}\end{array}$ & $\begin{array}{c}\text { Plantas coletadas } \\
\text { (estéreis) }^{\text {Plantas coletadas }}\end{array}$ & $\begin{array}{c}\text { (férteis) } \\
\mathbf{( 3 )}^{2}\end{array}$ \\
\hline FOM & 331 & 257 & 38 & 31 & 28 \\
FED & 251 & 176 & 43 & 21 & 18 \\
FOD & 559 & 257 & $70^{(2)}$ & 68 & 77 \\
\hline Média & 380 & 230 & 50 & 40 \\
\hline
\end{tabular}

(1) total de ambos os estratos; (2) 278 para área de $400 \mathrm{~m}^{2}$; ${ }^{(3)}$ inclusive levantamento florístico dentro e ao redor da UA.

\section{Levantamento florístico}

Este levantamento consistiu na coleta de todo o material fértil de espécies vasculares dentro da UA, independente do estrato e sub-área, nos arredores da UA e ao longo do caminho de acesso a ela. Sua importância ficou evidente durante a execução do IFFSC, quando as respectivas listas foram comparadas. A Tabela 4 mostra que o número de espécies encontradas aumentou significativamente com a realização do levantamento, o que permitiu uma caracterização mais detalhada e abrangente do fragmento florestal amostrado. Considerando apenas os estratos das plantas com $\mathrm{DAP} \geq 10 \mathrm{~cm}$ e da regeneração (com DAP $<10 \mathrm{~cm}$ ), a diversidade total encontrada foi de 875 espécies, sendo 566 comuns entre os dois estratos. No levantamento florístico foram registrados 1.085 espécies, das quais
539 exclusivas, elevando a riqueza registrada para 1.414 espécies (aumento de 62\%). Considerando ainda espécies epífitas e as pteridófitas (descontadas sete espécies de pteridófitas com feto arborescente, já incluídas no estrato com DAP $\geq 10 \mathrm{~cm}$ ), chega-se a uma riqueza total de 2.202 espécies vasculares, faltando ainda o processamento das coletas de $20 \%$ das UAs da FOD.

\section{Custos}

O IFFSC foi financiado pela Fundação de Apoio a Pesquisa Cientifica e Tecnológica de Santa Catarina (Fapesc), que disponibilizou R \$ 2,8 milhões para a realização do projeto entre 2007 e 2010 . A contrapartida da Universidade Regional de Blumenau somou $\mathrm{R} \$ 480.000,00$ para o mesmo período e consistiu no equivalente às horas-atividade dedicadas pelos professores gestores do projeto. 


\section{Custo (desembolso) por unidade amostral}

Na Tabela 5 são apresentados os custos médios por UA e por fase do projeto (no sentido de desembolso). $\mathrm{O}$ aumento do desembolso entre a segunda e a terceira fase foi causado pelo aumento das despesas com mão de obra dos técnicos e pela alteração da forma de sua contratação (de prestadores de serviço para contratos pela CLT). O aumento entre as fases 3 e 4 ocorreu devido às maiores dificuldades de acesso na FOD, à maior extensão dos remanescentes, à maior densidade, altura e diversidade das florestas e ao aumento da área amostral do estrato da regeneração de $100 \mathrm{~m}^{2}$ para 400 $\mathrm{m}^{2}$ por UA; à intensificação da amostragem das plantas epifíticas na FOD, realizada por equipes especializadas.

Tabela 4. Número de espécies encontradas por estrato, grupo e região fitoecológia (os totais $\neq$ às somas, devido às espécies que ocorreram em várias regiões fitoecológicas). Os dados da FOD incluem apenas 169 das 208 UAs previstas.

\begin{tabular}{|c|c|c|c|c|c|c|}
\hline $\begin{array}{c}\text { Região } \\
\text { fitoecológica }\end{array}$ & $\begin{array}{c}\text { UAs } \\
\text { processadas }\end{array}$ & $\begin{array}{c}\text { Estrato } \\
\text { DAP } \geq 10 \mathrm{~cm}\end{array}$ & $\begin{array}{c}\text { Estrato } \\
\text { DAP }<10 \mathrm{~cm}\end{array}$ & $\begin{array}{c}\text { Florística (arbórea, } \\
\text { arbustiva, ervas } \\
\text { terrícolas) }^{(1)}\end{array}$ & Epífitas $^{(1)}$ & Pteridófitas \\
\hline FOM & 151 & 404 (127) & $382(105)$ & 776 & 54 & 144 \\
\hline FED & 80 & $237(91)$ & $179(33)$ & 343 & 83 & 49 \\
\hline FOD & 169 & $556(123)$ & $578(145)$ & 875 & 368 & 281 \\
\hline Total & 396 & $710(144)$ & $731(165)$ & 1085 [539] & 483 & 312 \\
\hline
\end{tabular}

Tabela 5. Custo (desembolso) total médio por Unidade Amostral (UA) visitada do IFFSC, por fase, incluído o custo das unidades não levantadas (“descartadas") em R\$.

\begin{tabular}{|c|c|c|c|c|c|}
\hline Fase & Região Fitoecológica & $\begin{array}{l}\text { Número de } \\
\text { UA visitadas }\end{array}$ & $\begin{array}{c}\text { Custo médio por } \\
\text { UA (FAPESC) } \\
\text { R\$ }\end{array}$ & $\begin{array}{c}\text { Custo médio por } \\
\text { UA (FURB) } \\
\text { RS }\end{array}$ & $\begin{array}{c}\text { Custo total } \\
\text { RS }\end{array}$ \\
\hline $\begin{array}{l}\text { Fase } 2 \\
2007 / 2008\end{array}$ & FOM & 125 & $2.792,00$ & $1.096,00$ & $3.888,00$ \\
\hline $\begin{array}{l}\text { Fase } 3 \\
2008 / 2009\end{array}$ & FOM / FED & 156 & $5.551,28$ & 903,85 & $6.455,13$ \\
\hline $\begin{array}{l}\text { Fase } 4 \\
2009 / 2010\end{array}$ & $\mathrm{FOD}^{(1)}$ & 208 & $7.716,35$ & 971,15 & $8.687,50$ \\
\hline
\end{tabular}

O detalhamento do desembolso por UA da Fase 4 (FOD) consta na Tabela 6. Estão incluídos, de forma proporcional, os desembolsos do processamento de dados e de material botânico de cada UA, bem como o desembolso para planejamento e gerenciamento do inventário, sob forma do salário dos professores da FURB envolvidos, proporcional ao número de horas semanais dedicadas ao projeto.

\section{Remuneração de pessoal}

Os integrantes das equipes de campo e de escritório foram inicialmente contratados como prestadores de serviço autônomos. Esta forma de contratação de pessoas físicas, no entanto, é adequada e prevista na legislação apenas para serviços eventuais e de curta duração. Para as fases 3 e 4, colaboradores diretos foram contratados pela Universidade para todas as funções, através de contrato temporário com registro em carteira profissional. A remuneração mensal bruta do engenheiro florestal e do biólogo foi de $\mathrm{R} \$ 2.687,73$, do escalador $\mathrm{R} \$ 1.182,61$ e do auxiliar de campo R\$ 860,00 (março de 2010).

O período de trabalho foi estabelecido de forma que as equipes ficassem em campo durante duas semanas, trabalhando também aos sábados e folgando na semana seguinte. Assim, ocorreram um melhor entrosamento e uma melhor sequência de trabalho, além da redução de deslocamentos entre a base (Blumenau) e os locais de hospedagem nas diversas regiões do estado. O regime de trabalho de segunda à sexta-feira mostrou-se ineficiente, por resultar em apenas três dias de efetivo trabalho em campo por semana. 
Tabela 6. Custos (desembolso) por Unidade Amostral (UA), com base na Fase 4 do IFFSC, realizada na Floresta Ombrófila Densa; salários incluindo encargos sociais; taxa de câmbio em março de 2010: 1,80 R\$/US\$.

\begin{tabular}{llr}
\hline \multicolumn{1}{c}{ Classificação } & \multicolumn{1}{c}{ Especificação } & Valor por UA (R\$) \\
\hline Investimento patrimonial & Materiais permanentes campo & 869,70 \\
& Materiais permanentes processamento de dados & 33,55 \\
Mão-de-obra & Materiais permanentes herbário & 16,63 \\
& Salários de equipe de campo & $2.403,84$ \\
& Salários de equipe de herbário & 116,99 \\
& Salários de equipe de processamento de dados & 510,26 \\
& Salários professores FURB & 972,00 \\
Despesas gerais & Hospedagem & 572,58 \\
& Alimentação & 394,26 \\
& Aluguel de veículos & 435,12 \\
& Combustível & 95,56 \\
& Materiais de consumo campo & 121,25 \\
& Materiais de consumo herbário & 263,05 \\
\hline Subtotal & Materiais de consumo processamento de dados & 3,90 \\
\hline Levantamento de epífitas & Serviços de terceiros & 251,47 \\
\hline
\end{tabular}

Taxa de câmbio em março de 2010: 1,80 R\$/US\$.

\section{Discussão}

O IFFSC não foi concebido como teste metodológico para um inventário nacional, mas acabou cumprindo esta função, uma vez que foi o primeiro inventário estadual a aplicar a metodologia proposta para o IFN/BR. Sob alguns aspectos, a amostragem proposta do IFFSC foi mais intensiva que a do IFN/BR, sem deixar de ser compatível, pois é possível filtrar os dados de acordo com os critérios de inclusão do IFN/BR. Alguns detalhes metodológicos, não comuns em inventários florestais até o presente momento, serão discutidos a seguir, além de importantes lições que podem ser tiradas da experiência de quatro anos de execução do IFFSC.

$\mathrm{O}$ adensamento da grade de pontos amostrais com distância de $20 \mathrm{~km}$ para $10 \mathrm{~km}$ (e $5 \mathrm{~km}$ na FED) foi motivado pela superfície de apenas $95.000 \mathrm{~km}^{2}$ do território catarinense (resultando em baixo número de UAs), por sua grande variação geomorfológica, climática e de altitude, que resultaram em rica e diferenciada flora e vegetação (Klein, 1978), fragmentada e sob intensa perturbação antropogênica pretérita e atual, principalmente na FED e FOM (Vibrans et al., 2008). Grades com distâncias diferentes também são usadas no inventário nacional nos diversos biomas do México (Conafor, 2010) e em outros países como Alemanha, Japão, Polônia e Romênia (Tomppo et al., 2010).

Optou-se pela intensificação da amostragem da regeneração na FOD, após se constatar o reduzido número de indivíduos amostrados neste estrato na FOM e FED. Além de quadruplicar a área amostral para $400 \mathrm{~m}^{2}$ por UA, foi ampliado o critério de inclusão, de $1,50 \mathrm{~m}$ para $0,50 \mathrm{~m}$ de altura das plantas registradas; isto porque boa parte dos indivíduos das espécies arbóreas, devido ao seu crescimento lento e seu baixo número, podem não ser inclusos na amostra, indicando, falsamente, que determinada espécie não tenha regeneração. Entendeuse ainda que plantas com altura $\geq 0,50 \mathrm{~m}$ podem ser consideradas como definitivamente estabelecidas e não efêmeras. Embora a metodologia da FAO para inventários nacionais (FAO, 2009) e também outros inventários nacionais em regiões tropicais como o das Filipinas (Branthomme, 2002) apliquem neste caso a altura de 1,30 m, outros autores como Schreuder et. al. (1993) e Husch et al. (2003) recomendam incluir a regeneração a partir de uma altura de $0,30 \mathrm{~m}$, enquanto no México utiliza-se 0,25 m (Conafor, 2010). 
A descrição fisionômica da vegetação, bem como a das influências antrópicas constatadas em campo, juntamente com fotografias da vegetação, carta-imagens do fragmento e a tabela dos principais parâmetros estruturais da floresta formam um conjunto de valiosas informações de cada UA que se mostrou importante como auxílio à interpretação dos resultados quantitativos obtidos e deve ser incluída na rotina de inventários semelhantes, sendo que para muitos municípios ou localidades o IFFSC constituiu o primeiro registro de sua flora e vegetação.

A coleta de material botânico e a correta identificação das espécies foram consideradas de suma importância e foram realizadas no IFFSC com extremo rigor. Para tanto, a presença de um biólogo em campo, treinado e conhecedor da flora arbórea da região, mostrou-se essencial e indispensável. A substituição do trabalho da tradicional figura do "mateiro/identificador" (com conhecimento local valioso, mas restrito às denominações populares) pela identificação cientifica das espécies é imprescindível para os propósitos de inventários modernos, que visam embasar medidas de conservação e manejo das florestas. Diante da demanda de divulgar os resultados do IFFSC citando os nomes populares, foi trilhado o caminho inverso dos inventários tradicionais (IBDF, 1984), realizados quando não se dispunha de botânicos qualificados para o trabalho de campo: determinou-se primeiro o nome científico das plantas e posteriormente realizou-se pesquisa bibliográfica (Reitz, 1959, 1965-) para atribuir as mesmas denominações vernaculares, que podem resultar em significado mais concreto dos resultados.

A inclusão de levantamento florístico dentro e ao redor da UA resultou em significativo aumento das espécies registradas; estas, em conjunto com a descrição fisionômica da vegetação, auferiram maior consistência à caracterização dos remanescentes amostrados. $\mathrm{O}$ levantamento das epífitas por equipes especializadas foi realizado na FOD devido à importância desta sinúsia nesta região fitoecológica; ele representou uma importante inovação em inventários florestais, permitindo uma avaliação ampliada do conjunto da vegetação encontrada. O grande volume de plantas coletadas e processadas no herbário é uma consequência de uma abordagem mais detalhada e representa um desafio logístico importante e a ser considerado no planejamento de um inventário nacional. As experiências do IFFSC também mostraram que apenas uma pequena parte das UAs pôde ser levantada num único dia de trabalho. Na FOM e FED o tempo médio dispendido por UA foi de 1,5 dias, enquanto que na FOD foi de 3 dias.

A contratação de pessoas jurídicas para execução dos levantamentos de campo, utilizada em inventários nacionais no México ou nos Estados Unidos (Tomppo et al., 2010), não se viabilizou pela falta de empresas habilitadas e com corpo técnico adequado; pela imprevisibilidade do rendimento das equipes; por incertezas em relação à viabilidade dos procedimentos das diversas atividades em campo; por insegurança e atrasos do repasse de recursos que impossibilitaram, por fim, a realização de licitação prevista para contratação. O IFFSC foi iniciado com duas equipes de campo com seis integrantes cada, em novembro de 2007. O gradativo aumento da equipe do IFFSC de 18 pessoas em 2007 para 54 contratados em 2010, propiciada pela chegada de mais recursos financeiros, mostrou-se vantajoso porque os novos colaboradores puderam ser treinados com as equipes existentes e a sua capacitação deu-se de forma contínua. A manutenção de pessoal contratado em caráter permanente durante as etapas subsequentes do projeto permitiu a realização de um trabalho com maior qualidade e homogeneidade operacional. A contratação de técnicos que durante a sua graduação participaram de projetos de inventários e levantamentos florísticos, bem como de mestrandos nas áreas afins, trouxe ao trabalho eficácia e rigor na coleta e no processamento dos dados.

\section{Considerações finais}

O primeiro grande levantamento florístico-florestal realizado em Santa Catarina, coma instalação de 550 Unidades Amostrais, constituiu um grande desafio para as equipes envolvidas, tanto de campo como de escritório e herbário.

Apesar de não ter sido concebido com esta finalidade, o IFFSC serviu como um teste operacional de um inventário nacional. Alterações da metodologia como as do estrato da regeneração e das epífitas foram realizadas, mostrando que em um inventário desta natureza, mesmo com métodos bem definidos, ainda podem ser necessárias adaptações durante o processo de execução para melhorar os procedimentos de amostragem, de acordo com os objetivos propostos e tendo em vista a sua continuidade. 


\section{Agradecimentos}

Os autores agradecem à Fundação de Apoio à Pesquisa Científica do Estado de Santa Catarina (FAPESC) pelo suporte financeiro ao IFFSC. Agradecem pela colaboração na identificação das plantas às seguintes instituições e taxonomistas: UFSJ (Marcos Sobral); UFES - A. Lobão (Annonaceae); UFRGS - H. M. Longhi-Wagner (Poaceae), R. Trevisan (Cyperaceae), M. R. Ritter (Asteraceae - Mikania), A.A. Schneider (Asteraceae - Baccharis); UNICAMP: R.A. Camargo (Fabaceae); UFSC - M. L. D'E1 Rei Souza (Melastomataceae); UFMG - A. Salino (Pteridofitas); UEC - João Aranha (Symplocaceae); UFPR - R. Goldenberg (Melastomataceae), W. S. Mancinelli (Orchidaceae), E. Smidt (Orchidaceae); UFRRJ - A. Costa (Bromeliaceae); Conservatoire et Jardin botaniques de la Ville de Genève - A. Chautems (Gesneriaceae); JBRJ - A.L. Peixoto (Monimiaceae), D. P. da Costa (Briófitas), M. Bovini (Malvaceae, Bombacaceae, Tiliaceae, Sterculiaceae), S. Profice (Acanthaceae), M. Nadruz (Araceae e Elaeocarpaceae), R. C. Forzza (Bromeliaceae), C. Nicoletti (Orchidaceae e Dilleniaceae, Ochnaceae), V. Mansanno (Leguminosae), E. Guimarães (Piperaceae, Loganiaceae, Boraginaceae, Gentianaceae), Â. Vaz (Leguminosae), F. Freitas (Myrsinaceae e Cactaceae), A. Quinet (Lauraceae).

\section{Referências}

BRANTHOMME, A. National Forest Inventory Philippines. Field Manual. Roma: FAO Forestry Department. 2002. 67 p.

BRASIL. Resolução CONAMA n ${ }^{\circ} 278$ de 24 de maio de 2001. Diário Oficial [da] República Federativa do Brasil, Brasília, DF, 18 de jul. 2001.

BRASIL. Resolução CONAMA no 309 de 20 de março de 2002. Diário Oficial [da] República Federativa do Brasil, Brasília, DF, 29 de julho de 2002.

BRENA, D. A. Inventário Florestal Nacional: proposta de um sistema para o Brasil. 1995. 226 f. Tese (Doutorado em Ciências Florestais) - Universidade Federal do Paraná, Curitiba.

CALEGARI, J. Tamanho ótimo da unidade amostral para estudo da regeneração natural de uma floresta ombrófila mista. 1999. 90 f. Dissertação (Mestrado em Engenharia Florestal). - Universidade Federal de Santa Maria, Santa Maria.

CBD. The Convention on Biological Diversity. 1993. Disponivel em: <http://www.cbd.int/>. Acesso em 24 abr. 2010.

CTN-IFN/BR. Comissão Técnica Nacional do Inventário Florestal Nacional. Projeto Inventário Florestal Nacional. Brasília: SFB/ MMA. 2007. 148 p.
CONAFOR. Comisión Nacional Forestal. Inventário Nacional Florestal y de Suelos. Manual y Procedimientos para el muestreo de campo. Re-muestreo 2010. Zapopan: CONAFOR. 2010. 140 p.

FAO. National Forest Monitoring and Assessment-Manual for integrated field data collection. NFMA Paper37/N. Roma: FAO. 2009. 183p.

FUNDAÇÃO DO MEIO AMBIENTE DE SANTA CATARINA. Mapeamento temático geral do estado de Santa Catarina. Relatório Técnico (não publicado). Florianópolis: FATMA. 2008. 90 p.

FREITAS, J. V.; OLIVEIRA, Y. M. M. de; ROSOT, M. A. D.; GOMIDE, G.; MATTOS, P. P. de. Brazil. In: TOMPPO, E., GSCHWANTNER, T., LAWRENCE, M., Mc ROBERTS, R. E. National Forest Inventories. Pathway for Common Reporting. Heidelberg: Springer. 2010. 607 p.

HUSCH, B.; BEERS, T. W.; KERSHAW, J. A. Forest Mensuration. New York: John Wiley \& Sons, 2003. 443 p.

IBDF. Departamento de Economia Florestal (Brasilia, DF). Inventário florestal nacional: florestas nativas, Paraná, Santa Catarina. Brasília: IBDF, 1984. 309 p.

KLEIN, R. M. Mapa fitogeográfico do Estado de Santa Catarina. Itajaí: Herbário Barbosa Rodrigues, 1978. 24 p. (Flora Ilustrada Catarinense).

PÉLLICO NETTO, S. Die Forstinventuren in Brasilien: Neue Entwicklungen und ihr Beitrag für eine geregelte Forstwirtschaft. 1979. 232 f. Tese (Doutorado em Ciências Florestais) - Universität Freiburg.

QUEIROZ, W. T. Efeitos da variação estrutural em unidades amostrais na aplicação do processo de amostragem em conglomerados nas florestas do Planalto Tapajós. 1997. 109f. Dissertação (Mestrado em Ciências Florestais) - Universidade Federal do Paraná, Curitiba.

REITZ, P. R. Os nomes populares das plantas de Santa Catarina. Sellowia, Itajái, v. 11, n. 11, p. 9-148, 1959.

REITZ, R. Flora Ilustrada Catarinense, 1965 - . Itajaí: Herbário Barbosa Rodrigues.

SAR. Secretaria de Agricultura e Abastecimento do Estado de Santa Catarina. Inventário Florístico Florestal de Santa Catarina:

Relatório do Projeto Piloto. Florianópolis, SC: Mimeo, 2005. 170 p.

SHIVER, B. D.; BORDERS, B. E. Sampling Techniques for Forest Resource Inventory. New York: John Wiley \& Sons, 1996. 350 p.

SCHREUDER, H. T.; GREGOIRE, T. G.; WOOD, G.B.

Sampling Methods for Multiresource Forest Inventory. New York: John Wiley \& Sons, 1993. 446 p.

TOMPPO, E., GSCHWANTNER, T., LAWRENCE, M., Mc ROBERTS, R. E. National Forest Inventories. Pathway for Common Reporting. Heidelberg: Springer. 2010. 607 p.

UNITED NATIONS. Kyoto Protocol to the United Nations Framework Convention on Climate Change. 1998, 20 p. Disponivel em : < http://unfccc.int/resource/docs/convkp/kpeng. pdf $>$. Acesso em 24 abr. 2010.

VIBRANS, A. C.; UHLMANN, A.; SEVEGNANI, L.; MARCOLIN, M.; NAKAJIMA, N.; GRIPPA, C. R.; BROGNI, E.; GODOY, M. B. Data ordination of mixed rain forest structure based on information of Floristic Forest Inventory of Santa Catarina State, Southern Brazil: results of a pilot survey. Ciência Florestal: v.18, n. 4, p. 511-523, 2008. 